\title{
Albert Alexander Gray, M.D.
}

Albert Alexander Gray died on January 4, I936, aged sixty-seven years. Born in Glasgow on October 8, 1868, he studied medicine at the University, qualifying in $\mathrm{I} 890$, and taking his doctor's degree seven years later. After spending two years in general practice, he commenced the study of otology, working in Leipzig and Munich. He finally settled in Glasgow, where he became Surgeon on Diseases of the Ear at the Western Infirmary, and Lecturer in Diseases of the Ear in the University.

Coming early under the influence of Professor J. G. McKendrick, Gray collaborated with him in the preparation of the chapters on the ear and vocal sounds for Sharpey-Schafer's Text-book of Physiology, published in I900. But it was as a scientific worker in the laboratory that Gray soon made his reputation as the leading otologist in this country. Devising a method of preparing the labyrinth, or internal ear, for purposes of investigation by dissolving the bony capsule and leaving the membranous labyrinth exposed through the almost transparent endosteum, he was thus able to study its form. In two large volumes on The Labyrinth of Animals, published in 1907 and 1908, he produced a series of stereoscopic pictures of great beauty displaying the comparative anatomy of that structure in the animal kingdom. This work was received with general acclamation by otologists all over the world. He extended the knowledge of the pathology of congenital deaf-mutism by a method of preparation of the cochlea which permitted his obtaining microscopical sections of great delicacy. During his later years he contributed several valuable papers upon the subject of tumours of the eighth cranial nerve. The pathology of otosclerosis, also, will always be associated with Gray's name, a subject on which he did much important work, publishing his book, in I9I 7, under the title of Idiopathic Degenerative Deafness.

Gray's labours were recognised by his contemporaries and did not pass unrewarded. In 1909 he gained the Lenval Prize in Otology; in I9I I he was Gold Medallist of the American Academy of Ophthalmology and Otology. In 1929 he received the Guyot Quadrennial Prize of the University of Groningen, and in 1933 the Dalby Memorial Award. He was frequently honoured by being placed in the presidential chair at various otological conferences.

Modest, unassuming, and of a sociable disposition, Albert Gray had many friends who enjoyed his companionship and rejoiced in the welldeserved honours conferred on him.

He was elected a Fellow of the Society in 1898 .

A. L. T. 